
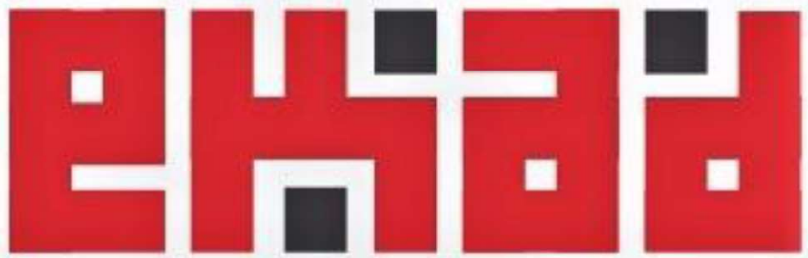

INTERNATIONAL JOURNAL OF LANGUAGE, LITERATURE AND CULTURE RESEARCHES

МЕЖДУНАРОДНЫЙ ЖУРНАЛ ЛИНГВИСТИЧЕСКИХ,

ЛИТЕРАТУРОВЕЛЧЕСКИХ И КУЛЬТУРОЛОГИЧЕСКИХ ИССЛЕЛОВАНИЙ

Vol: 4, Issue: 2, 2021

Sayfa-Page: $274-285$

E-ISSN: $2667-4262$

\title{
DİL-KÜLTÜR ETKİLEŞİM ÖRNEĞİ OLARAK RUSÇADA SAATLERİN İFADESİ
}

\section{EXPRESSION OF TIME IN RUSSIAN AS AN EXAMPLE OF LANGUAGE-CULTURE INTERACTION}

\section{Leyla Cĭğdem DALKILIC *}

\begin{tabular}{|c|c|}
\hline MAKALE BİLGİSİ & ÖZET \\
\hline $\begin{array}{l}15.09 .2021 \\
12.11 .2021\end{array}$ & \multirow{3}{*}{$\begin{array}{l}\text { Dil ve kültür ilk başta birbirinden bağımsı iki olguymuş gibi görünmesine rağmen, biri } \\
\text { diğerini tamamlayarak belirli bir külttür anlayış içerisinde harmanlanan halkın dilini } \\
\text { anlamamıza yardımcı olur. Belirli bir dünya görüşü temelinde şekillenen halkların dillerini } \\
\text { öğretirken eğitmenler zorlu süreçlerle karşıllaşabilmektedirler. Dilde var olan her olguyu } \\
\text { anlamlandırmak her zaman mümkün olmasa da kültür temelinde bir bakış açısı } \\
\text { kazandırabilmek sadece o dili değil o dili konuşanları da anlamaya yardımcı olabilmektedir. } \\
\text { Rus dili ile ilintili olarak dil eğitiminde Türk dili konuşucuları için alışılmadık olan bir } \\
\text { kullanım mevcuttur. Bu da Rusçada buçuk ve geçe ifadeleri ile aktarılan zaman dilimlerinin } \\
\text { hâlihazırda akıştaki saatle değil bir ileri rakam ile ifade edilmesidir. Bu çalışmada Rus } \\
\text { dilinde buçuk ve geçe ifadeleri ile aktarılan zaman dilimlerinde, Türkçede belirgin olan } \\
\text { zaman diliminin ifadesi yerine bir ileri saat diliminin kullanımının ardında yatan olası } \\
\text { sebepler incelenmekte ve ortaya konmaya çalışıllmaktadır. İnceleme insan modelli zaman } \\
\text { algısının kültürün de etkisiyle dile nasıl yansıdığını ortaya koymayı amaçlamaktadır. Bu } \\
\text { amaçla, gelenekselleşmiş zaman modellerinden olan döngüsel ve çizgisel modeller ile Eski } \\
\text { Slav halklarının zamana ilişkin mitlerinin Rus dünya görüşünde saatlerin ifadesine nasıl } \\
\text { yansımış olabileceği ele alımmaktadır. }\end{array}$} \\
\hline $\begin{array}{l}\text { Anahtar Kelimeler: } \\
\text { Saat, } \\
\text { zaman, } \\
\text { kültür, } \\
\text { dil, } \\
\text { Rusça. }\end{array}$ & \\
\hline Araştırma Makalesi & \\
\hline
\end{tabular}

ARTICIF INFO

\section{ABSTRACT}

Received: 15.09 .2021

Accepted: 12.11 .2021 the elements that help us to understand the language of the people, which is blended in a certain cultural understanding by completing one another. While teaching the languages of people, which have been shaped on the basis of a certain worldview, the educators may come across some difficulties. Although it is not always possible to understand every phenomenon in a language, bringing a cultural perspective can help to understand not only that language, but also those, who speak it. In teaching Russian as foreign language there is an unusual usage of some language units for the Turkish language speakers. In the expressions, used with the words 'half', 'quarter' (or minute) we name the hour, which is coming next. In this work, it is studied and tried to identify the possible reasons for the expression of the next hour, conveyed by means of words 'half ','quarter' (or minute) in the Russian language, in contrast to the Turkish language, in which the time is conveyed more concisely. The study aims to reveal, how the human-modeled perception of time is reflected in the language under the influence of culture. For this purpose, it is discussed how cyclical and linear models, which are traditional models of time, and the myths of the ancient Slavic people regarding 24-hour day could be reflected in the Russian worldview while expressing time.

* Doç. Dr., Ankara Üniversitesi, Dil ve Tarih- Coğrafya Fakültesi, Slav Dilleri ve Edebiyatları Bölümü, Rus Dili ve Edebiyatı Ana Bilim Dalı, Ankara / Türkiye. E-mail: lcdalkilic@ankara.edu.tr.

ORCID (D) https://orcid.org/0000-0001-8801-6792.

Bu makaleyi şu şekilde kaynak gösterebilirsiniz / To cite this article (APA):

Dalkılıç, Leyla Çiğdem (2021). "Dil-Kültür Etkileşim Örneği Olarak Rusçada Saatlerin İfadesi”. Uluslararası Dil, Edebiyat ve Kültür Araştırmaları Dergisi (UDEKAD), 4 (2): 274-285. DOI: https://doi.org/10.37999/udekad.995785. 


\section{Extended Abstract}

Language is a phenomenon which has evolved by itself, has developed over time, the initial date of which is not entirely clear, but culture exists with the active participation of people. In fact, there is a clear relationship between these two phenomena, one of which seems to exist independently of the person, and the other with the human factor. It is a known fact that the culture of the people plays a role in shaping the language of these people. In this regard, one phenomenon not only complements the other, but also plays an important role in understanding the pecularities of the language, which are formed under the influence of culture and mentality of the people who speak this language. In this respect, language perfectly reflects the cultural and intellectual heritage of the people within the language-person-culture triangle. While it is not always possible or easy to understand every phenomenon in a language, it is important to understand these complex phenomena of the language, to make them meaningful, to find connections in terms of facilitating both learning and understanding processes and to offer a new point of view. The expression of time in Russian language is different from the Turkish. Turkish native speakers express hours in Turkish the same way as in English; they express hours using the numbers they use in a specific order in the language. On the other hand, the expression of hours with the words "half", "quarter" (or minute) in Russian is unusual for native speakers of the Turkish language, because in Russian the expression of time with these words is made by not using the current hour, but the next one. The expression of this unusual usage of time for the Turkish mentality can be based on several reasons. With a cyclical model of time whicht is as old as the history of mankind and which evolved as a reflection of human life experience life flows in a repeating cycle. Natural phenomena, sunrise and sunset, hot, dry, snowy or windy weather, etc. (depending on the season) are all arranged in a specific order. Humans, just like nature, are always in motion by virtue of their existence. This state of being in motion shows, that people will always move forward in the same circle of cycles, following in the footsteps of their ancestors. Proceeding from their past habits, people can confidently move into the future, since the past is always repeating itself and the future, in a certain course of action, gains absolute confidence. In this respect the Russian speaker, expressing the time of the next hour, moves his discourse forward, leaving the present moment and knowing that events will repeat in a cyclical pattern. The person, who goes out of the current moment, moves forward in the repetitive cycle by changing his point of view on the event. Another thought on this subject is related to the mythical consciousness and culture of the Ancient Russian people. Again, the problems arising from the role of nature, the human existence and caused by such consequences as a warm stroke, sunstroke, etc. led to the fact, that noon was remembered in human consciousness and thus remained in the memoriy as a bad, not very favourable time. The midday demon, which takes place in the mythological consciousness of the Russians, probably has shown itself as if it had negative connotations for the Russians, and its reflection in the language could show itself in the form of avoiding of usage of certain time intervals or their rapid omission. The last thought, which can clarify this issue, is that in traditional folk culture, the ancient Slavs evaluate the world around them, dividing them into two separate classes, such as good-bad, positive-negative, favorable-dangerous. In the names, used to denote time, some concepts such as morning-evening, night-day, light-dark are quite clear, while the expressions such as noon and midnight are more ambiguous. This uncertainty in time expressions has also been shaped in relation with human activities. There is a morning or daytime, when a person begins working, starting from the moment when he/she wakes up, and there is an evening or night time when he/she finishes the work he/she has started. Noon, which is an intermediate time interval, is not fixed in the consciousness clearly in comparison with other time of the day, since it is not fixed with a clear action. In this regard, since concepts, such as good and bad, used to denote time, and intermediate time, such as noon are associated with negative connotations and these time intervals are not assigned to a specific action, the expression of day and noon in the language is aimed more to show the time to come next, than to convey that very moment.

\section{Giriș}

Dil başlangıç tarihi tam olarak belli olmayan bu bakımdan da kendiliğinden ortaya çıkarak zaman içerisinde gelişim gösterdiğini söyleyebileceğimiz bir olgudur, kültür ise, insanın aktif katılımı ile vardır. Dil kuramları dilin ne zaman ve nasıl ortaya çıktığına dair somut bilgileri ortaya koyamadığından dil-insan ilişkilerini net bir şekilde tanımlamak mümkün görünmemektedir ve bu açıdan biri insandan bağımsız diğeri insan faktörü ile varmış gibi 
görünen bu iki olgu arasında esasında belirgin bir ilişki mevcuttur. Bir halkın kültürünün o halkın dilinin şekillenmesinde rol oynadığı bilinen bir gerçektir. Bu bakımdan bir olgu diğerini sadece tamamlamakla kalmamakta, aynı zamanda kültürün de etkisiyle ortaya çıkarak şekillenen dilin özelliklerini, buradan hareketle de bu dili konuşan halkların düşünce yapısını anlamamızda önemli bir görev üstlenmektedir. Belirli bir dünya görüşü temelinde şekillenen halkların dillerini öğretirken eğitmenler zorlu süreçlerle karşılaşabilmektedirler. Dilde var olan her olguyu anlamlandırmak her zaman mümkün olmasa da kültür temelinde bir bakış açısı kazandırabilmek sadece o dili değil o dili konuşanları da anlamaya yardımcı olabilmektedir. Rus dili ile ilintili olarak dil eğitiminde Türk dili konuşucuları için alışılmadık olan bir kullanım mevcuttur. Bu da Rusçada buçuk ve geçe ifadeleri ile aktarılan zaman dilimlerinin hâlihazırda akıştaki saatle değil bir ileri rakam ile ifade edilmesidir. Bu çalışmada Rus dilinde buçuk ve geçe ifadeleri ile aktarılan zaman dilimlerinde, Türkçede belirgin olan zaman diliminin ifadesi yerine bir ileri saat diliminin kullanımının ardında yatan olası sebepler incelenmekte ve ortaya konmaya çalışılmaktadır. İnceleme insan modelli zaman algısının kültürün de etkisiyle dile nasıl yansıdığını ortaya koymayı amaçlamaktadır. Bu amaçla, gelenekselleşmiş zaman modellerinden olan döngüsel ve çizgisel modeller ile Eski Slav halklarının zamana ilişkin mitlerinin Rus dünya görüşünde saatlerin ifadesine nasıl yansımış olabileceği ele alınmaktadır.

\section{Rusçada Geçeli ve Buçuklu Zaman İfadeleri}

Bireyin dünya görüşünü anlayabilmemize yardımcı olması açısından dil, kültürün en önemli katmanlarından bir tanesini oluşturur. Kültürü oluşturan önemli bir katman olmasının yanı sıra dil, bireyin yaşadığı ve bir birey haline geldiği ortamı, yaşam tecrübesini de anlamamıza yardımcı olur. Bu açıdan dil, dil-insan-kültür üçgeni çerçevesinde düşünce ve kültür miraslarını en iyi biçimde yansıtmaktadır. Dil ve kültür arasındaki ilişki kültür bilimcilerin, felsefecilerin ilgisini çektiği kadar dilbilimcileri de yakından ilgilendirmektedir. Dilbilimcilerin veya dil eğitmenlerinin bu iki olgu arasındaki ilişkiyi belirgin bir şekilde hissettikleri nokta ise, ana dilleri dışındaki yabancı bir dili incelerken veya bu dilin eğitimini verirken yaşanmaktadır. Dili anlama ve anlamlandırabilme ihtiyacı eğer diller farklı dil ailelerine mensupsa ve dillerin özünü anlamlandırabilmek için verilen gramer kuralları yeteri kadar açıklayıcı değilse bu ihtiyaç bilhassa belirgin olarak kendisini hissettirmektedir. Söz gelimi, Rusça ve Türkçe farklı dil ailelerine mensup iki dil olarak son yıllarda öğrenimi hızla artan dillerdendir. Doğal olarak da hem öğrenen hem de öğreten için zorlayıcı, kimi zamanda anlaşılması zor noktalar olabilmektedir. Dildeki her olguyu anlamlandırmak her ne kadar mümkün veya kolay olmasa da dildeki bu zorlayıcı olguları anlamlandırmaya çalışmak, anlamlı kılabilmek, bağlantılar bulabilmek hem öğrenme süreçlerini hem de anlama süreçlerini kolaylaştırabilmeleri, yeni bir bakış açısı sunabilmeleri açısından önemlidir. Rus ve Türk dilleri birçok açılardan birbirinden ayrılmaktadır. Bu ayrımlar sadece dilin morfolojik yapısı, gramer kuralları çerçevesinde değil, bizi çevreleyen dünyanın gerçeklerinin dildeki ifadesine de yansımaktadır. Dünya gerçeklerinin dile aktarımları esnasında kelimeler haricinde başvurduğumuz en önemli olgulardan bir tanesi de zaman kavramıdır. Dil ve kültür arasındaki bağı zaman çerçevesinden devam ettirecek olursak, kültürün bir ürünü olarak şekillenen zaman anlamlarının dildeki ifadelerinin, kişinin algıladığı zamansal boyutun kültürle harmanlanan dünyevi tecrübelerinin bir sonucu olarak dile yansıması olduğunu söylemek mümkündür. E. L. 
Golovyeva (2008: 113), doğa bilimleri çerçevesinde zaman kavramına yönelik geliştirilen yaklaşımdan farklı olan zaman ile kişinin yaşadıklarıyla şekillenen zamanın, her zaman için düz bir çizgide ilerlemediğini, tersine çevrilebilir olduğunu, her zaman için eş zamanlı olmadığını, bölünebilir olduğunu dile getirmektedir. Bu yaklaşımın bir yansımasını da tıpkı Rusçada gramer çerçevesindeki zaman dilimlerinin Türkçede farklı şekillerde aktarılmalarında olduğu gibi, kimi saatlerin ifadelerinde de görebiliriz. Bu açıdan Rusçadaki saatlerin aktarımı Türkçedekinden farklıdır. Türk dili konuşucuları Türkçede saatleri ifade ederken, sözgelimi tıpkı İngilizcede olduğu gibi, saatleri dilde belirli bir sıralamaya oturttuğu rakamları kullanarak ifade etmektedir. Rusçada ise, buçuklu ve geçeli ifadelerinin aktarımı Türk dili konuşucuları için alışılmışın dişındadır, çünkü Rus dilinde bu saatlerin ifadesi görülen rakamın aktarımını değil, görülen rakamdan gelen bir sonraki sayının söylenmesi ile ifade bulur.

Rusçada saatleri aktarırken öncelikle öğretilen, asal sayıların ismin yalın haldeki formları ile sira sayıların ismin tamlama hallerindeki yapılarıdır: один-первого, два-второго, тритретьего, четыре-четвёртого vb. Bunun dışında saniye, dakika, saat gibi zaman birim ölçüleri ile günün akışını belirleyen gündüz, akşam, gece gibi isimler verilir. Tam saatlerin aktarımı, verilen zaman ile asal sayı arasındaki uyumu sağladığından tıpkı Türkçede de olduğu gibi, doğrudan ifade edilir: 14:00 (два часа - saat iki), 17:00 (пять часов - saat beș), 22:00 (десять часов - saat on) vb. Buna karşılık buçuklu ve geçeli saatlerde bir sonraki saat kullanılır:

- пол пятого ${ }^{1}=16.30$

- семнадцать третьего ${ }^{2}=14.17$

- двадцать восемь шестого ${ }^{3}=17.28$

- тринадцать минут восьмого ${ }^{4}=07.13$

- четверть четвёртого ${ }^{5}=15.15$

- четверть второго ${ }^{6}=13.15$

Örneklerde de görüldüğü üzere, Rusçada buçuk ve geçe ifadeleri ile aktarılan zaman dilimlerinde hâlihazırda akıştaki saat değil bir ileri rakam kullanılır. Rus dilinde yarım anlamını veren пол (pol) ifadesi Hint-Avrupa kökenli olup eski Hintçede görülen ve "tahta, parça" anlamlarına gelen phálakham sözcüğü ile Eski İspanyolcada "yarım, tahta, parça" anlamlarına gelen fjol sözcükleri ile aynı ortak aileden gelmektedir. Eski Rusçaya kelime поль şekli ile girmiş olup başlarda "temel” (основание) anlamıyla anılmıştır (EOS) ${ }^{7}$. Yoğun olarak XI-XIV. yüzyıllarda Eski Rusça metinlerde sayı yapıları ile aktif bir şekilde kullanılmaya başlanmış olan

\footnotetext{
${ }^{1}$ Пятый - beş(inci) anlamına gelir. Varlıkların anlam incelemesinde öğrenciler çoğunlukla şekilden anlama yöntemi ile ifadelere yaklaşırlar. Sözcüğün iç anlamından ziyade ifade yapısı ön planda tutulur. Bu bakımdan, öğrenci şekilden anlama yöntemi ile ifadeyi deşifre yoluna gittiğinde verilen ifadeyi gördüğü șekliyle okuduğundan verilen zaman ifadesi 17.30 şeklinde algılanabilir, ancak 16.30'a tekabül eder. Aynı durum açıklaması aşağıda verilen diğer zaman ifadeler için de geçerli olacaktır.

${ }_{2}^{2}$ Третий - üç(üncü) anlamına gelir. Şekilden anlama yöntemi ile gidildiğinde 15.17 olarak yorumlanabilir.

${ }^{3}$ Шестой - altı(ıncı) anlamına gelir. Şekilden anlama yöntemi ile gidildiğinde 18.28 olarak yorumlanabilir.

${ }^{4}$ Восьмой - sekiz(inci) anlamına gelir. Şekilden anlama yöntemi ile gidildiğinde 08.13 olarak yorumlanabilir.

${ }_{5}^{5}$ Четвёртый - dört(düncü) anlamına gelir. Şekilden anlama yöntemi ile gidildiğinde 16.15 olarak yorumlanabilir.

${ }^{6}$ İki(nci) anlamına gelir. Şekilden anlama yöntemi ile gidildiğinde 14.15 olarak yorumlanabilir.

${ }^{7}$ Etimologiçeskiy online slovar' russkogo yazıka Marksa Fasmera, Kısaca: EOS
} 
пол/половина (pol/polovina) ifadelerine yönelik olarak yapılan günümüz Rus dili çalışmalara bakıldığında kimi araştırmacıların пол ifadesinin bağımsız yapısından sıyrılarak bir ek haline dönüştüğünü, isim olarak adlandırılamayacaklarını dile getirdikleri, bazılarının ise bunun sözcükselleşmiş ve isim yapısındaki sözcüklerden farklı birtakım kullanım özelliklerine sahip olan kelimeler olarak varsaydıkları, diğer bir grup bilim insanının ise bunları sayı olarak adlandırdıkları görülmektedir (Molkov 2016: 117-119). Farklı adlarla ve farklı dil kategorilerine ait oldukları atfedilerek belirli bir sınıfa sokulmaya çalışılan söz konusu ifadeler, XVIII. yüzyıla ait metinlerde çoğunlukla sayı kategorisinde ve "bir şeyin ortası, tarafi, yarısı" (середина, сторона, половина) anlamlarıyla sözcüklerle birlikte kullanılmış, XVIII. yüzyılın üçüncü çeyreğinde ise tam ve sıra sayılarıyla kullanıldıkları gözlemlenmiştir (Molkov, 2016, s. 123, 130). İsim ve sayı grubundaki sözcüklerin yanı sıra zaman anlamını veren yac, yaca (saat) gibi ifadelerle de nadiren de olsa yan yana geldikleri gözlemlenmektedir. Buna karşılık araştırmacı G.A. Molkov, pol/polovina ifadelerini incelediği çalışmasında bu sözcüklerin diğer kavramsal özelliklerin aktarımının yanında, saat anlamlarının kullanımlarının çok az sayıda olduğunu dile getirmektedir (2016: 139). Bununla birlikteMolkov, ismin tamlama hali olan roditelnıy padej (родительный падеж) уарısıyla birlikte kullanılan bu ifadelerin anlamsal olarak değişken özellikler gösterebildiğini, bu anlamlardan bir tanesinin ise, herhangi bir şeyde belirli derecede bir belirginlik ortaya koyamama, "belirgin olarak bir özelliğin tezahür edememesi” olduğunu, verdiği полбеды, полгоря, полдела örnekleri ile açıklamaktadır (2016: 138). Tümün yarısının da yarısı anlamındaki четверть (çeyrek) ifadesi ise, Eski Slavcada "dördüncü" anlamına gelen (четвёртый - četvьrtъ) kelimesinden türemiştir (EOS). Yarım ve çeyrek anlamlarını dildeki ifadelere bir belirsizlik, bir şeyin yarısı veya bir noktanın ilerisi, sonrası, tam olamama gibi ifadelerin Rus dilinde zaman anlamlarına yansımasında, hele ki Rus dilinde zamanın Türkçe için alışılmadık bir düzlemde aktarılmasının ardında, halkın dünya görüşü ile kültürün etkilerinin dile yansımalarının yattığı düşünülmektedir.

İnsan varlığı ve bilincinin ayrılmaz bir parçası olan zaman evrensel olmasının yanı sıra, her bir halkın, bireyin zaman algısı kendine hastır. Bu bakımdan halkların dil dünya görüşünün yansitılmasında temel bir role sahiptir. Nesnel bir biçimde var olan zaman ve mekân, öznel olarak insanlar tarafından algılanıp yaşanmaktadır: "farklı toplumlarda, toplumun farklı evrim süreçlerinde, aynı toplumun farklı kesimlerinde ve hatta ayrı bireyler tarafından bu kategoriler farklı biçimlerde algılanıp uygulanmaktadır... Birey zaman kavramı ile doğmaz, onun zaman ve mekân algısı her zaman ait olduğu kültür ile belirlenir (Gureviç 1971:159). Bu bakımdan toplumların tarihsel gelişim süreci içerisinde gelişen zaman algısının oluşumunda döngüsel zaman, mitolojik zaman, döngüsel-tarihsel zaman gibi farklı kavramlar, farklı modeller ortaya çıkmıştır (Smolina 2001: 33). Beşerî bilimler de kendi sınıflandırmasını ve zaman modellerini ortaya koymuştur. En çok bilinenler arasında tarihi zaman, sosyal zaman, bireysel zaman gibi sınıflandırmalar yapılmıştır (Miheeva, 2016). Çağdaş dilbilim ve felsefe bilimleri çerçevesinde en geniş kabul gören dilsel zamanın incelendiği zaman modellerinden ikisi, "ilk kez Fransız felsefeci Jean-Marie Guyau tarafindan 1890 yllinda kaleme alinan 'proishojdeniye idei vremeni' (zaman fikrinin kökeni) döngüsel zaman ve çizgisel zaman modelleridir. Döngüsel zaman imgesel bir algl temelinde ilkel toplumlarda oluşan bir dizi fikrin yansıması olarak sunulmaktadır" (Miheeva 2006: 149). Döngüsel zaman kavramı, mit dünya görüşünü yansıtan 
bilinç olarak ifade edebileceğimiz mitlerin şekillendirdiği ilkel insanın bilincinde yer eden hayatın, mevsimlerin döngüsünde olduğu gibi dönemsel olarak ritüeller ve mitlerle canlılığını tazeleyen ve sürekliliğin sağlandığı bir anlayıştan ileri gelmektedir. Mit dünya görüşünü yansıtan bilinç (mitsel dünya algısı) insanı doğadan ayrı tutmaz bir bütün olarak sonsuz döngüsünü, sonsuz bir çarkın hareketi ile bağdaştırır, bu bakımdan çember ya da daire, bu döngüsel zamanın sembolik işaretini yansıtır, sonsuzluk kavramı ise, başlangıç ve sonu olmayan dairenin kapalılığından ileri gelir (Miheeva 2006: 149). Gündüz-gece, yaşam-ölüm, bahar-kış, gibi doğanın çevriminin gündelik hayata yansıması olarak döngüsel zaman, tekrar edilebilir, geriye dönülebilir, ilkel insan hem şimdiki zamanın gerçekliği içinde hem de sonsuz sürekli bir dizi içerisinde var olur (Ünlü 2009: 63). Zaman sadece döngüsel olarak yaşanılan bir kavram olmaktan çıkıp algılanmaya, hissedilmeye, tarihte yaşanan olaylar belirli bir sıraya konmaya başlanınca çizgisel zaman modeli doğmuştur. Tekrar etmez, daima ileriye doğru akan bir değişim, dönüşümden bahseden bir anlayışa bağlı olarak ortaya çıkmıştır, geçmiş-şimdikigelecek zaman çizgisinde ileriye doğru hareketi göstermektedir.

Rus dilbilimci N. D. Arutyunova'ya (1997: 53) göre, yaşam zaman içerisinde ve onun kanunlarına göre akmaktadır. Zaman gibi, insan yaşamı da geri dönülemez, düz bir çizgi üzerinde ilerler. Yeryüzünde zamanın vücut bulması onun sonsuz olan ile olmayanın ayırt edilmesini sağlamaktadır. İnsan geçmişe anıları, pişmanlıkları, üzüntüleri, tecrübe ve bilgileri ile bağlıdır. Gelecekte ise istekler, ümitler, korkular, ön görüler, tasarı ve planlar yer alır. Şimdi ise yok gibidir yalnızca gerçeklikle olan doğrudan iletişim durumları söz konusudur. İnsan, ancak şimdide vardır. Alman filozof Heidegger'e (1993: 399) göre ise, insanın dünyada var olması formal zamanı olaylarla doldurmaktadır, kişinin zaman algısı ise zaman hakkında "gelecek, tamamlanmış ve mevcut olanın karşılıklı bir uzantısının bütünü" olarak konuşmamıza olanak sağlamaktadır. Bu açıklamalardan görülebileceği üzere zamanın tek başına varlığı, insan faktörü söz konusu olduğunda zaman modellerinin ortaya çıkmasıyla farklı boyutlarda belirginlik kazanmaktadır. Varoluşun temelinde bulunan insan, zamanı bileșenlerine göre bir çıkış noktası veya varoluş noktası bir de çıkıştan itibaren ilerleyen hareket noktası olmak üzere iki birbirine zıt görünen bir anlayış ile açıklamaya çalışmıştır. Var oluş noktası, bakış açısını yansıtırken, hareket noktası ise olayların gerçekleştiği ilerleyen zamana işaret etmektedir. Hareket halinde iken bakış açısı değişmekte, mesafeler uzayıp kısalmaktadır. Çıkış noktası veya varoluş noktası olan "Şimdi" noktası, geleceğe doğru ilerlemektedir (Arutyunova 1997: 53). İnsan faktörü ile ortaya çıkan zaman modellerini insan yolu model ve doğal akış modeli olarak ikiye ayıran Arutyunova (1997: 54), insan yolu modelde hep bir ileriye gidiş söz konusu olduğunu açıklar: "Insan yolu model hep hareket (идmu, приходить, проходить, приближаться, наступать) ve hareket ile ilintili yer ve yön isimleri (перед, позади, назад, после, следом) ӥzеrine kuruludur. Geleneksel yolda insanlar atalarının izinden ilerliyorlar, yüzleri belirsiz geleceğe değil, geçmişe dönük." Bu ifadelerden insanların geçmişteki alışkanlıklardan yola çıkarak geleceğe emin adımlarla yönelebildikleri, çünkü geçmişte olan hep tekrar ettiği için bu düzen içerisinde geleceğin de kesinlik kazandığı anlaşılmaktadır.

Tüm bu yaklaşımların 1şı̆̆ında, iki temel zaman modeli esasında birbirini tamamlamaktadır. Döngüsel zaman modeli ile doğanın hareketlerine bağlı olarak tekrar eden olaylar, çizgisel zaman modeli içerisinde belirli bir yere sahip olarak devam ederek 
tekrarlanmaktadır. Şimdi, geçmiş ve gelecek olarak bildiğimiz zamanın döngüsel, tamamlanmış ve tekrar eden modelleri insanlık tarihinden çok önceleri var oldukları, doğa ile ilintili olduklarından tüm dünya halkları için birdir, aynı şeyi bir yıllık ve günlük döngüler için de söylemek mümkündür. Buna karşılık, bu zamansal döngülerin zaman dilimlerine, saatlere ayrılması insan yaşamının, tecrübelerin bir ürünüdür (Tolstoy 1997: 17). Dilin tarihsel gelişimi içerisinde zamanın, insan eliyle belirli saat dilimlerine ayrılması ve dil dizgesinde biçimlendirilmesi o halkın dil dünya algısını yansıtır.

İnsan yaşamındaki tüm varlığın belirleyicisi olarak güneşin döngüsü ile belirginlik kazanan bu döngüsel zaman modeli, Slav halklarının da yaşamlarında belirleyici olmuştur. Eski Slavlar yılı dört bölüme değil, aydınlık ve karanlık kavramlarıyla yaz ve kış olmak üzere ikiye ayırmışlardır. Yılın bu şekilde ayrılması Slav halk bayramlarındaki kutlamalara ve geleneklere de düşünsel olarak yansımıştır. Söz gelimi yaz ve kış döngülerinin kutlandığı İvan Kupala ve Svyatki halk bayramlarında kutlamalar bayram öncesi ve bayram sonrası ${ }^{8}$ olmak üzere ayrılmaktadır. Eski Slav halklarının kış gündönümü bayramı olan Kolyada'nın bir uzantısı olan Svyatki günümüzde, Noel (veya Rojdestva Hristova) ${ }^{9}$ zamanı kutlamalarının tümünü kapsayan ve Hz. İsa'nın doğumu ile (24 Aralık gecesi) Vaftiz Bayramı'na (6 Ocak) kadar olan dönemi kapsayan on iki günlük süre içerisindeki kutsal gün etkinlikleridir. Günümüzde bu bayram diğer Slav ülkelerinde hala kutlanmakla birlikte, Rusya'da Noel adı altında daha çok ön plandadır, bu bakımdan Noel yortusuyla Vaftiz Arifesi arasındaki bayram kutlamalarının tümünü kapsamaktadır (Şangina 2008: 17). On iki günlük kutsal gün döngüsü eski ile yeni y1l arasında bir köprü olarak görülmektedir. İlk altı günlük süre kutsal akşamlar olarak adlandırılırken, geri kalan altıncı gün korkunç akşamlar olarak ifade edilir. Bayram öncesi ve bayram sonrası kutlamalar için yapılan hazırlıklar, gündüz işlerin yerine getirilerek tamamlanması, akşam ise kutlamalara geçilmesi, eski yılın son bulup yeni yılın başlaması, kış güneşinin yaza dönüşmesi gibi bu bayramın her bir noktasında ikiye bölünme söz konusudur. Buradan hareketle bazı kavramlar, örneğin gündüz ve gece (ya da akşam) daha belirgin iken, ara vakitler daha siliktir. Yine Eski Slav halklarının Güneş ve Yazın Olgunluğu Bayramı olarak kutlanan İvan Kupala yaz gündönümünün kutlandığı bir yaz başı bayramıdır. Bu ve bunun gibi birçok eski halk bayramında gündüz ve gecenin zitlı̆̆ , diğer bir deyişle, güneşin doğduğu andan itibaren yayılan aydınlık ve güneşin battığı andan itibaren yayılan karanlık çerçevesinde gündüz ve gecenin (veya akşam) daha keskin çizgilerle ayrıldığını, bu ayrımın kutlamalar, uygulanan ritüeller gibi halkın gelenek ve göreneklerine de yansıdığı bu açıdan dilde söz konusu kavramların daha baskın olduğu görülmektedir. Sanki gündüz ve gece, aydınlık ve karanlık mevcuttur ve görülmektedir, ancak öğlen gibi ara zaman dilimleri geri planda kalmıştır. Bir zıtlık diğer bir zıtlığın ortaya çıkmasını daha da belirginleştirerek tam zıtlık oluşturmaktadır, ara zamanlarda ise, örneğin, öğlen, öğlen vakti, öğle sonrası gibi iki kavram arasında araya bir veya birkaç öğenin girdiği karşıtlık türlerinde ise kavramlar tam bir zıtlık vermezler. Bu ve benzeri ifadeler, dilde kesişen öğelerin karşıtlığı kavramı ile adlandırılır (Novikov-Zubkova vd. 2003: 234). Kelimelerin işlevi ve anlamı kısmi olarak uyum gösterse de belirli farklılıklar vardır. Gündüz-

\footnotetext{
${ }^{8}$ Buradaki "sonra" ifadesi tamamlanmış bir şeyden ziyade, anın gelişi sonrasına vurgu yapmaktadır.

${ }^{9}$ Hz. İsa'nın doğumunun kutlandığı zaman dilimini kapsar. Ayrıca Doğuş Bayramı, Kutsal Doğuş veya Milat Yortusu olarak da bilinir.
} 
gece, sabah-akşam nasıl kesin olarak tam bir zıtlık veriyorsa, sabah-öğle-öğle sonrası ifadeler aydınlık kavramı içerisinde adlandırılabilecek olsa da biri diğerine tam bir zıtlık göstermez, bu bakımdan diğer sözcüklere oranla öğle vaktine ilişkin kavramsal bir belirsizlik de söz konusudur.

Öğle vakti gibi ara zaman dilimlerinin geri planda kalmasının, bu bağlamda da dil içerisinde bazı ifadelerde çok da belirgin olmamasının izleri Eski Slav halklarının yirmi dört saatlik zaman dilimine yani bir güne yönelik dünya görüşlerinde de gizli olabilir. Eski Slavlarda bir gün gündüz ve gece olarak ayrılmakta, ara geçiş zamanları olarak ise gün doğumu ve gün batımı şeklinde ele alınan sabah ve akşam vakitleri ile öğlen ve gece yarısı sıralanmaktadır. Gün doğumunda ya da günbatımında sabah ve akşam vakitlerinde büyü ve şifa uygulamaları yapılır; gece yarısı ve öğlen ise, doğaüstü varlıklar ve kötü ruhlar bu zamanları sevdiğinden bunların gücünden sakınmak, bu zaman dilimlerinde dikkatli olmak gerekir: “...bu zaman diliminde kötü ruhlar ve buna benzer yaratıklar insanı yiyebilir, alay edip üstüne çıkabilir, kire çamura bulayabilir" (Tolstoy 1997: 24). Her inanç ve düşünce sisteminde olduğu gibi karanlık ve kötü güçlerin varlığına tüm yüzyıllar boyunca inanılmıştır. İkili denge unsurunun bir sonucu olarak ortaya çıkan karanlık güç inancı bazı zaman dilimlerine olan yaklaşımda belirleyici olmuştur. Daha çok güneş battıktan sonra kendini gösterenlerle birlikte gündüz vakti mevcut olanları da vardır. Gece vakti belirenlere nazaran daha az bilinmelerine rağmen, Eski Slavlar için öğle vakti ortaya çıkan iki öğlen iblisi vardır, bunlardan biri Ruslarda poludnitsa (полудница) olarak adlandırılan ve kadın figüründe beliren, korkunç bir görüntüye sahip veya tam tersi çok güzel bir surette, tam öğle vaktinde, buğdayların çiçeklenmesi ve olgunlaşması sırasında tarlalarda ortaya çıkabilen diğeri ise poludzennik olarak adlandırılan ve erkek suretinde korkunç bir biçimde ortaya çıkarak küçük çocuklar için tehlike oluşturan öğlen iblisleridir (Tolstoy 1997: 25). Bu mitolojik karakter Ukrayna, Belarus ve Rusya arasında bulunan Polesiye (Pripert Havzası), Rusya'nın kuzeyinde yer alan Arhangelsk bölgesinin en eski yerleşim bölgelerinden biri olan Pinegra, Belarus'un güney-batı bölgelerinden Homel bölgesini kapsayan topraklarda yaygın olarak bilinmektedir. Polonya topraklarında da bilinen bu su iblisi daha çok erkek suretinde olup, insanları boğmaktadır (Levkievskaya-Usaçeva 1995: 154). Belarus'un Homel bölgesinde Velikoe pole köyünde yaygın olarak bilinen yaratığın öğle vakti aktif olarak ortalıkta gezindiğine ve kıyıya çıktığına inanılmaktadır, bu nedenle su iblisi kaçırmasın diye yüzmek isteyen çocuklar öğle vakti (saat 12.00'de) nehre salınmazdı (Levitskaya-Usaçeva 1995: 157; Levkievskaya 2001: 439). Bu varlığın saat 12.00 ila 14.00 arası aktif, nadiren de 11.00 ila 12.00 arasında ortaya çıktığına inanılmaktaydı. Eski Slavlarda yine öğle vakti ile ilintili olarak öğlen kelimesinin kökünden türeyen bu mitolojik karakterin başka adlarına da rastlanmıştır. Doğal olmayan yollarla ölen bir öğlen iblisini ifade etmek için kullanılan -pol köklü bu isimlere Rusya'nın kuzeyinde poludzennik, Çeklerde poludnice, farklı ağızlarda yaramaz çocukları boğan kadın yaratık olarak polednice, Slovaklarda poludnica, Lehlerde öğle vakti tarlalarda ortaya çıkan tarla cini przypoludnica olmak üzere rastlanmaktadır. Yine Rusya'nın Kuzeyi'nde poludzennik haricinde poludennik (полуденник) olarak da adlandırılan öğlen iblisinin açık bırakılan bebek beşiğine sokulabileceği de ifadelerde yer alır (Levkievskaya-Usaçeva 1995: 158). Öğlen iblisinin varlığına yönelik inanç, bilhassa yukarıda ifade edilen bölgelerin yanı sıra, Rusya'nın kuzey-batısı olan Arhangelsk, 
Olonetskaya (Petrozavodsk), Novgoroskaya, Yaroslavskaya, Volgodskaya, Vitebskaya ve Smolensk bölgeleri ile Perm ve Sibirya'da yaygındır (Dınin 1994: 115). Öğlen iblisinin Doğu Slavlar içerisinde bilhassa Rus halkı arasında bu kadar yaygın olması, onun eski bir mit olduğunu göstermekte bu bakımdan da öğle vaktinin Ruslar başta olmak üzere Eski Slavlarda olumsuz bir çağrışıma sahip olduğu görülmektedir. Bu mitolojik varlık, insanları boğmasının yanı sıra "güneş çarpması, kızgın öğle saatleri ile eski inançların pagan varlıkları ve şeytanları"yla da ilişkilendirilmektedir (Tokarev 2012: 84).

Geleneksel halk kültüründe Slavların, dış dünyanın da etkileriyle zamanı olumluolumsuz, iyi-kötü, elverişli-tehlikeli gibi sınıflara bölerek değerlendirdikleri de ayrıca görülmektedir. Zamana yönelik olarak kullanılan iyi ve kötü kavramları dilde bir şekilde ifadelerde yer bulurken, kimi durumlar için hiç yer etmeyebilir. Öğlen vaktinin bu olumsuz çağrışımının, kendini dilde belirli saat dilimlerinin ifadesinde bir atlama şeklinde yansıtmış olabileceği düşünülebilir. Belki de geçeli saatlerin bir ileri saatle ifadesi, belirli zaman aralıklarının hızlıca atlanarak geçilmek istenmesinin bilincini bizlere yansıtmaktadır.

Rusçada öğlen vaktine yönelik yukarıda bahsedildiği şekliyle oluşmuş olan bu yaklaşım kısmi olarak dilde kendi göstermektedir. Söz gelimi, sabah, akşam hatta gece kelimeleriyle birçok edat, sıfat, zarf yan yana gelirken öğle vakti biraz daha bu anlamda geridedir. Krş.: sabah - утром, поутру, с утра, под утро, утречком, с утречка, раннее утро, позднее утро; akşam - вечером, вечерком, с вечера, вечерок, поздний вечер vb. Öğle vakti ise, başta birçok Avrupa ülkesinde olduğu gibi, saat 12.00 ila 14.00 arasında bulunan "öğle yemeği” kavramı ile daha çok ilişkilendirilmektedir (Zaliznyak-Şmelev 1997: 237). Bu aradan önceki zaman dilimi yani gece yarısından öğle yarısına kadar olan zaman ise Rusçada çoğunlukla "sabah" olarak adlandırılmaktadır. Bu aradan sonraki zaman dilimi ve tahminen iş gününün sonuna kadar olan ve İngilizce afternoon, Fransızca apres-midi, Almanca nachmitting, İtalyanca pomeriggio sözcükleri ile ifade edilen zaman aralığının Rusçada tam olarak bir karşılığı bulunmamaktadır (Zaliznyak-Şmelev 1997: 237). Bazı metin içi bağlamlarda bu kavram öğleden sonra (nocлe полудня, послеполуденный) уа da sadece gün anlamına gelen день kelimesi ile aktarılmaktadır. Öğleyin, öğlen anlamına gelen днём kelimesi Rusçada sınırları belli olmayan bir zaman dilimine işaret eder: "sabahın erken saatleri değil, akşam olmadan önceki zaman aralı̆̆gl" (Zaliznyak-Şmelev 1997: 237). Bu kelimenin Rusçada belirsiz kalmasının sebebi dilde zaman kavramlarının kişilerin eylemleri ile ilintili olarak anlam kazanmalarında yatmaktadır, başka bir deyişle bu zaman aralığında yapılan veya yapılacak olan eylemlerin kişilerin yaşam akış sürecinde belirsiz kalmasından kaynaklanmaktadır. Söz gelimi sabahın ilk ışıkları, sabahın erken saatleri yani gündüz vakti eğer tarlada, bayırda, yaylada, çadırda, barakada, ağılda, evde vb. yerlerde yapılacak olan işler, hasadı toplamak, tarlayı sürmek, ekmek, biçmek gibi eylemlerle belirli ise, herkesin dinlenip bir köşesine çekileceği akşam olmadan önceki zaman dilimi de esasında gündüzden kalan işlerin bir devamı niteliğinde düşünüldüğünden Rus dünya görüşü için bu zaman aralığı sanki belirsiz gibidir. Bu bakımdan, "Rusçada zaman bakımından belirli sınırları olmayan bir aradadır, sabah insanların gündüz vakti eylemlerini yerine getirdiği, akşam ise gündüz vakti eylemlerinin sona erdirildiği zamandır.

Zaliznyak-Şmelev (1997: 239) bir günü kapsayan Rus zaman modelinde uyanma anı, ișe başlama anı ve gündüz eylemlerinin bitirilmesi anlarının önemli olduğunu, bilhassa Batı 
Avrupa zaman modelinde ise, gece yarısı ve öğleden sonrası anların daha ön planda olduğuna vurgu yapmaktadırlar. Bu bakımdan Rus dünya görüşüne göre, sabah ve akşam vakitleri tezahür ettikleri anda yapılan eylemler ile doldurulduğundan, öğle vakti anının bu dünya görüşüne göre belirgin bir eylem ile sabitlenmediği anlaşılmaktadır.

\section{Sonuç}

Varoluş kategorisinin önemli bir parçasını oluşturan ve dil sistemlerinden ayrı olarak düşünülemez olan zaman kavramı bir milletin kültürü ve dünya algısı ile şekillenerek en somut biçimde dildeki ifadelerde yerini alır. Yapılan inceleme sonucunda, Rusçada geçeli ve buçuklu saatlerin ifadesinde, Türk algısı için alışılmadık olan zaman diliminin bir ilerisinin ifadesi birkaç sebebe dayandırılabilir. Öncelikle dilin morfolojik yapısı baz alınarak buçuk ve geçeli saatlerde ileri bir saat diliminin ifade edilmesine ilişkin bir çıkarımda bulunacak olursak, yarım ve çeyrek ifadelerinden sonra dilin tarihi gelişim süreci içerisinde bu sözcüklerin ismin tamlama hali ile kullanılması sonucunda "yarım" anlamının sayılarla bir bütünlük oluşturduğu görülmektedir. Söz gelimi, beş buçuk, yedi buçuk gibi saat dilimlerinde (пол шестого (pol şestovo - 6.30, пол восьмого - 7.30) bir ileri saat diliminin kullanılması, "altının yarısı" yani beş buçuk, "sekizin yarısı" yani yedi buçuk gibi sözcüksel olarak ifade bularak dildeki yarım anlamı ile özdeşleşmiştir. Benzer ifade özelliğini "çeyrek" kelimesinin kullanımlarında da görebiliriz. Semantik açıdan geçeli ve buçuklu saat dilimlerinin ifadesinde "bir bütünlüğün değil bir şeyin yarımı" anlamı dilde hâkim anlam olarak sabitlenmiştir. Bu bakımdan şekil olarak görülen zaman dilimi değil, sıra veya asal sayıların birlikte kullanıldıkları "yarım" ve "çeyrek" ifadeleri anlam şekillendirici olarak karşımıza çıkmaktadır. Rus dil eğitiminde varlıkların adlandırılmasında öğrencilerin şekilden anlama yöntemini benimsemeleri buçuk ve geçe kavramları ile aktarılan zaman dilimlerinin algısını güçleştirmektedir. Bu nedenle bilhassa bu zaman dilimlerinin algısında anlamdan şekle gidilmesi diğer bir değişle varlıkların adlandırılmasının anlamsal yönünden ifadesel yönüne yapılması bu bakımdan buçuklu ve geçeli ifadelerde "bir kavramın yarısı" anlamı önem taşımaktadır.

Halkın kültürü ve mit bilincinin bir yansıması olarak bu zaman aralığının yansımasına bakacak olursak, döngüsel zaman modeli belirleyici bir role sahiptir. İnsanlık tarihi kadar eski olan ve yaşam tecrübelerinin bir yansıması olarak ortaya çıkan döngüsel zaman modeli ile yaşam tekrar eden bir döngüde akmaktadır. Doğa olayları, güneşin doğuşu ve batışı, mevsimlere göre havanın sıcak, kuru, karlı veya rüzgârlı vb. geçecek olması hepsi belirli bir düzene oturtulmuştur. İnsan da tıpkı doğa gibi, varoluşu gereği hep bir hareket halindedir. Bu hareket halinde olma durumu insanların, atalarının izinden giderek hep aynı döngü çemberi içerisinde ileriye hareket edeceklerini gösterir. İnsan geçmişteki alışkanlıklarından yola çıkarak geleceğe emin adımlarla ilerleyebilmektedir, çünkü geçmiş hep tekrar ettiği için belirli bir hareket düzeni içerisinde gelecek, mutlak bir kesinlik kazanmaktadır. Bu bakımdan Rusça konuşucusu, saatleri ileri bir sayı ile ifade ederken bulunduğu andaki varlığın dişına çıkarak ve olayların döngüsel modelde tekrar edeceğini bilerek söylemini ileriye taşımaktadır. Hâlihazırdaki anın dışına çıkan insan, olaya bakış açısını değiştirerek tekrar eden döngü içerisinde ileriye doğru gitmektedir. Bu konuya ilişkin bir başka düşünce de Eski Rus halklarının mit dünya görüşünü yansıtan bilinç ve kültürüyle ilintilidir. Yine doğanın rolünün, insanın varoluşunun bir uzantısı sonucunda ortaya çıkan sıcak çarpmasının etkileri ile oluşan 
rahatsızlıklar, güneş çarpması gibi olumsuzluklar kendisini, insan bilincinde öğle vaktinin olumsuz ve çok da uğurlu, iyi olmayan bir zaman aralığı olarak hatırlanmasına ve bu şekilde hatıralarda kalmasına neden olmuştur. Rusların mitolojik bilincinde yer eden öğlen iblisi, Ruslar için bu vaktin negatif konotasyonlara sahip olmasına yol açarak dile yansımasını belirli zaman aralıklarının dildeki ifadelerinden kaçınılması veya hızlıca atlanıp geçilmesi şeklinde kendini göstermiş olabilir. Bu konuya açıklık getirebilecek son bir düşünce ise, geleneksel halk kültüründe Slavların kendilerini çevreleyen dünyadaki varlıkları iyi-kötü, olumlu-olumsuz, elverişli-tehlikeli gibi iki ayrı sınıfa ayırarak değerlendirmesidir. Zamana yönelik olarak kullanılan adlarda, sabah-akşam, gece-gündüz, aydınlık-karanlık gibi kavramlar daha bir belirginliğe sahip iken öğle, gece yarısı gibi ifadeler daha belirsizdir. Zamansal ifadelerdeki bu belirsizlik, insan faaliyetleri ile ilintili olarak da şekillenmiştir. İnsanın uyandığı andan itibaren işe başladığı bir sabah veya gündüz ve başladığ işleri de bitirdiği bir akşam veya gece vakitleri vardır. Ara bir zaman dilimi olan öğle vakti ise, belirgin bir eylemle sabitlenmediğinden yine diğer türlere oranla açık bir belirginlikle bilinçlerde sabitlenmemiştir. Bu bakımdan, zamana yönelik olarak kullanılan iyi ve kötü gibi kavramlar ile öğle vakti gibi ara zamanlar hem olumsuz çağrışımlarla ilintili olduğundan hem de bu zaman aralıkları belirli bir eylemle sabitlenmediğinden dildeki ifadesi daha çok o anı aktarmaktan ziyade ileriye yöneliktir.

\section{Etik Beyan}

Yazar beyanına göre; "Dil-Kültür Etkileşim Örneği Olarak Rusçada Saatlerin İfadesi" adlı çalışmanın yazım sürecinde bilimsel, etik ve alıntı kurallarına uyulmuş; ULAKBİM TRDizin ölçütlerine göre çalışmada etik kurul onayını gerektiren herhangi bir veri toplama ihtiyacı duyulmamıştır.

\section{Kaynakça}

Arutyunova, Nina (1997). "Vremya: modeli i metaforı". Logiçeskiy analiz yazıka: yazık $i$ vremya. Ed.: Nina Arutyunova-Tatyana Yanko. Moskva: İndrik. 51-61.

Ünlü, Aslıhan (2009). Döngüsel zamanın Türk tiyatrosundaki döngüsü. Tiyatro araştırmaları dergisi, 28 (2): 61-90.

Dınin, Vladimir (1994). "Rusalki i poludnitsı: nekotorıe osobennosti mifologiçeskogo obraza rusalki u vostoçnıh slavyan”. Jurnal etnografiçeskoe obrazovanie, 6: 111-121.

Etimologiçeskiy online slovar' russkogo yazıka Marksa Fasmera . Erişim tarihi 09.11.2021, https://lexicography.online/etymology/vasmer/\%D0\%BF/\%D0\%BF\%D0\%BE\%D0\%BB

Golovleva, Yelena (2008). Osnovı mejkulturnoy kommunikatsii. Rostov-na-Donu: Feniks.

Guryeviç, Aron (1971). "Predstavleniye o vremeni v srednevekovoy Yevrope". Ístoriya $i$ Psihologiya. Moskva: Nauka. 159-198.

Heidegger, Martin (1993). Vremya i bitıye. Moskva: Respublika.

Levkievskaya, Yelena-Usaçeva, Valentina (1995). "Poletskiy vodyanoy na obşeslavyanskom fone". Slavyanskiy i balkanskiy folklor: Etnolingvistiçeskoe izuçenie Polesya. Ed. Nikita Tolstoy-Svetlana Tolstaya. Moskva: İndrik. 153-172. 
Levkievskaya, Yelena (2001). "Demonologiya severorusskogo sela Tihmangi." Vostoçnoslavyanskiy etnolingvistiçeskiy sbornik: issledovaniya i materiall. Ed. Anna Plotnikova. Moskva: İndrik, 432-476.

Miheeva, Lyubov (2006). "Yazıkovoe vremya kak lingvokulturologiçeskaya universaliya: mejdistsiplinarnıy podhod k izuçeniyu". Vestnik gumanitarnogo fakulteta İGHTU, 1: 145151.

Miheeva, Lyubov (2016). "Vremya v russkom yazıkovom soznanii. Nauçnıy Rezultat, Pedagogika i psihologiya obrazovaniya." Jurnal nauçnıy rezultat: pedagogika i psihologiya obrazovaniya. T. 2 (1): 57-63 http://rrpedagogy.ru/journal/article/709/

Molkov, Georgiy (2016). "İstoriya slova pol 'polovina' v russkom yazıke XVIII v. (po materialam kartoteki slovarya russkogo yazıka XVIII v.)". Russkiy yazık v nauçnom osveşenii, № 2 (32), 115-142.

Novikov, Lev-Zubkov, Lyudmila vd. (2003). Sovremennıy russkiy yazık: Fonetika. Leksikologiya. Slovoobrazovanie. Morfologiya. Sintaksis. Sankt-Peterburg: Lan.

Smolina, Anastasiya (2001). "Modeli vremeni i temporalnı konstruktsii". V konferentsiya studentov $i$ molodih uçenth Volgograda i Volgogradskoy oblasti: filosofskie nauki i kulturologiya, istoriçeskie issledovaniya. 21-24 noyabrya 2000. Volgograd: izd. VolGU. 33-35.

Şangina, İrina (2008). Russkie traditsionnie prazdniki. Sankt-Peterburg: Azbuka-klassika.

Tolstoy, Nikita (1997). "Vremya v slavyanskom mire: Vremeni magiçeskiy krug (po predstavleniyam slavyan)". Logiçeskiy analiz yazıka: yazık $i$ vremya. Ed.: Nina Arutyunova-Tatyana Yanko. Moskva: İndrik. 18-27.

Tokarev, Sergey (2012). "Polevik i poludnitsa". Religioznıe verovaniya vostoçnoslavyanskih narodov XIX -naçala XX veka. Moskva: Librokom.

Zaliznyak, Anna-Şmelev Aleksey (1997). "Vremya sutok i vidı deyatelnosti". Logiçeskiy analiz yazıka: yazık i vremya. Ed.: Nina Arutyunova-Tatyana Yanko. Moskva: İndrik. 231-240. 